(ARTS questionnaire), improvement of pain and functionality (WOMAC), improvement in perceived quality of life (EuroQuol 5), improvement of the degree of self-care to achieve a good management of the disease (IC, MPOC and TAC programs), improvement in therapeutic compliance

Results: Stage I initial presentations have been conducted at 8 out of 20 centers in urban and semi-rural areas to account for different social, economic, education and lifestyle demographics. Participants surveyed: 305 ; Interest in being a smart patient: 76; Interest in participating in the program: 193; No interest: 36; Level of satisfaction: $>90 \%$ reporting good or very good.

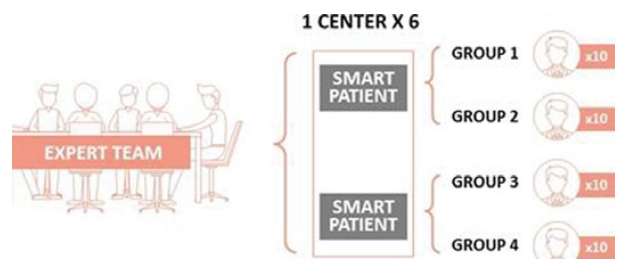

Conclusions: Based on results to date, after the 20 sessions the team expects to collect 763 surveys and identify 190 potential smart patients and 483 people willing to participate in the program. There is a clear interest or concern for OA disease in elderly people and they want to take more responsibility for their disease and age with quality of life.

References:

[1] Global Burden of Disease Study 2013 Collaborators, The lancet, June 8, 2015.

[2] Osteoarthritis - An Overview, Frost \& Sullivan, May 17th 2007.

[3] EPISER STUDY 2001, Spanish Rheumatology Society.

Disclosure of Interest: None declared

DOI: 10.1136/annrheumdis-2017-eular.3180

\section{PARE0018 WE DO THE IMPOSSIBLE, BECAUSE THE POSSIBLE EVERYONE CAN DO WAD AWARENESS CAMPAIGN}

\section{H. Bankova, B. Ivkov, S. Bozhinova, B. Boteva. BOPRD, Sofia, Bulgaria}

Background: One of the main priorities that Bulgarian organization for people with rheumatic diseases follows is dissemination of knowledge and information about RMD'S and their impact on people's life and to the society.

The WAD awareness campaign is the culmination of the organization's activities during the whole year.

Objectives: The main goal of the 2016 WAD awareness campaign was to:

- Inform the society and BOPRD's members about the social importance of RMD's.

- To inform BOPRD's members what are their rights as people with long term chronic condition.

- To inform the society about RMD's and the challenges that people with RMD's face.

- To challenge the people with RMD's to look into their inner world and to define what are their strengths and weaknesses.

- To make the informing process more attractive, by visualizing the key features of life with an RMD.

Methods: In 2016 BOPRD organized an awareness campaign - "We do the impossible, because the possible everyone can do"

The start of our campaign was on 1st of October and lasted for more than two weeks till the World arthritis day and ended on 16th of October. Informative and motivating pictures, with information about different RMD's, were published every day on the official BOPRD's Facebook page and were shared in the closed group for people with rheumatic diseases as well.

A social experiment among the members of the organization was made. They were asked to explain what the disease means to them, like they are telling the story to a person who do not know anything about it.

The aim of this experiment was to identify the meaning and significance which people with rheumatic diseases give to their condition, as well as the basic problems result from the illness.

Based on the social experiment and analysis of 33 small biographical narratives 17 basic characteristics of the rheumatic diseases are identified. These characteristics form the problematic areas for people with RMD's and bases for their study. The main characteristics are life with chronic pain, the process of disabling, life in continuous compliance with the environment and the high degree of uncertainty and ambiguity, imposed by chronic illness.

An e-booklet, containing the results of the social experiment was published on BOPRD's Facebook page and website on 12th October. On the same day we published the WAD video, of the PARE WAD campaign: "The future is in your hands". At the end of the awareness campaign we published an online booklet, which contained translated articles about RMD's and the different aspects of life with a chronic condition.

Results:

- The total number of all publications is 22 .

- The publications were seen from over 3000 people.

- The WAD video was seen by 1000 people.

- The results of the social experiment were seen by 1500 people.

- The most popular were those pictures that managed to touch people's feelings.

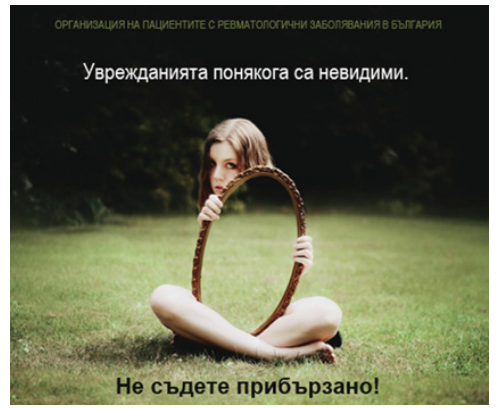

Conclusions: Main common characteristics of rheumatic diseases were identified and can help patients in getting the right diagnosis.

The most popular were the posts that were related to emotions and experience of life with a chronic condition.

By publishing the results of the social experiment we managed to help those who read the narratives get the feeling that they are not alone.

The results of the social experiment will be used as a basis in developing a manual for the main symptoms of RMD's (the patient perspective)

Acknowledgements: Miglena Ivanova

Cveta Apostolova

Disclosure of Interest: None declared

DOI: 10.1136/annrheumdis-2017-eular.3095

\section{PARE0019 ADHERENCE TO THERAPY: A COMPARISON BETWEEN THREE PATIENTS POPULATIONS WITH AUTOIMMUNE INFLAMMATORY DISEASES}

U.G. Viora ${ }^{1}$, R. Giannelli ${ }^{2}$, M.G. Pisu ${ }^{3}$, G. Voltan ${ }^{4}$ on behalf of ANMAR Italia. ${ }^{1}$ Anmar Italia, Torino; ${ }^{2}$ Anmar Italia, Firenze; ${ }^{3}$ Anmar Italia, Milano; ${ }^{4}$ Anmar Italia, Roma, Italy

Background: Non-adherence to therapy is one of the main obstacles achieving the goals of care in chronic autoimmune inflammatory diseases, including Rheumatic diseases (RMDs). In the "MOSAICO" study, ANMAR along with two other associations of Italian patients (AMICI chronic inflammatory bowel diseases (IBD) and ANAP - psoriasis (PSO) and chronic dermatological diseases) wanted to compare the adherence to therapies for IBD, RMDs and PSO and identify key problems that can affect it positively or negatively. This paper presents the results related to adherence to treatment, the obstacles that are disadvantageous and to the factors that, conversely, favor adherence and persistence.

Objectives: to fix the degree of adherence to therapy - with DMARDs and biological indifferently - in the three different pathologies; to identify obstacles and factors predisposing good adherence and persistence by patients; to compare the three different populations, highlighting similarities and significant differences Methods: a 72 questions questionnaire - about $50 \%$ of which were dedicated to adherence and persistence to therapy and the predisposing factors and impediments - prepared in collaboration with Doxapharma was administered to patients with RMDS, IBD, PSO via web and by volunteers of the three associations. The evaluation of adherence to therapy ("degree in which a person's behavior in taking medication, following a diet and/or change the lifestyle, corresponds to the specific recommendations made in agreement with the Medical") was assessed by Morisky Medication Adherence Scale - 8 items (MMAS-8)

Results: 1.017 patients - 233 with RMDs (AR e SA), 449 with IBD (Crohn and ulcerative colitis), 273 with PSO and 62 APs -answered to the questionnaire useful for the purpose of the study.

Non-adherence varies in a range from $50 \%$ of dermatological patients, to $44 \%$ of them with IBDs, to $40 \%$ of patients with APs, to $36 \%$ of them with RMDs. Only $74.8 \%$ of adherent people is persistent $(83 \%$ in biologic therapy; $76 \%$ in DMARDS) and non-persistent patients does not ask and/or inform their doctors.

Patients with Psoriasis take therapies more discontinuously and inaccurately then all the others.

Promote adherence:

- good support from doctors and health professionals

- satisfaciton with information received

- the best QOL

- easiness and lack of problems in taking drugs

- satisfaction with the therapy

- biologic therapies (even for the best QoL ensured)

Promote discontinuity and non-adherence:

- dissatisfaction with the relationship with doctors and health professionals $(33 \%$ $\div 70 \%$ of patients is dissatisfied)

Conclusions: Our study shows that patients who enjoy a better health state, both physically and psychologically, are more likely to follow the treatment prescribed by their doctor, according to the mode and the specified time, especially if properly informed and well supported in choices, shared by medical and health professional staff.

Disclosure of Interest: None declared

DOI: 10.1136/annrheumdis-2017-eular.3102 